\title{
correspondence
}

\section{The teratogenic effects of dioxin}

SIR,-Alistair Hay (10 February) states that many pregnant women from the dioxin-contaminated district of Seveso have sought terminations outside Italy. Some will have to come to Britain: UK statistics should reveal whether relatively more abortions were performed on Italian women in 1976 than 1975.

In view of the highly teratogenic activity of dioxin in animals, and the total absence of information for our own species, I share Dr Hay's concern that no organised steps have been taken to examine aborted foetuses for possible malformations. I would urge that some code of practice be agreed, if possible for Europe as a whole but at least for Britain, to ensure that ali foetuses aborted as a result of any suspected contamination of the environment should be examined by an experienced pathologist and compared with a matched control series. We may be too late this time: but Seveso is unlikely to be the last accident of its kind.

$$
\text { Yours faithfully, }
$$

ANNE MCLaren

MRC Mammalian Development Unit, University College, London

\section{Journal abbreviations}

SIR,-I agree with Adrian Smith (10 February, page 492) that the saving in typesetting does not in itself justify the use of journal abbreviations. I suggest, however, that the real problem lies not in abbreviating but in establishing a correct and unambiguous title. Here the British Standard is of no help, but the World List of Scientific Periodicals is invaluable, for journals published up to 1960 .

The examples of ambiguous abbreviation cited by $\mathrm{Mr}$ Smith do not come from the World List, where there is a clear distinction between J. math. Phys. and J. Math. Phys. Had they existed in 1960, Industrie minérale would have become Industrie minér, while Industrial Minerals became Ind. Miner. Even in the annual supplements published since 1960 , which have unfortunately abandoned the principles of the fourth edition of World List, Ind. Miner. $(F r)$ is not the same as Ind. Miner.

The World List gave a standard for journals with multilingual titles, and distinguished, if distinction be thought necessary, between three journals called Nature.

Correct identification of current journals will eventually be possible by the use of International Standard Serial Numbers, though whether this will reduce the chore to authors and editors remains to be seen.

Yours faithfully,

J. E. M. HoRne

Freshwater Biological Association, Windermere

\section{Charged plumes}

SIR,-Contrary to the report of Jennings and Jones on high electric fields from industrial stack plumes (November 18, 1976), the electrical effects in the atmosphere caused by electrostatic precipitators are well known. Those working in the field of atmospheric electricity are aware that plumes emanating from chimneys equipped with precipitators contain large numbers of charged particles which can be detected at a considerable distance from the chimney ${ }^{1}$.

Much of the charge may be carried on solid particles which somehow have escaped capture on the precipitator surfaces. We think that some fraction of the charge is also carried by water molecules from the combustion products in the industrial operation and of course there will be some small ion generation from the breakdown of other gases near the high voltage portion of the precipitator.

We have measured effects of chimney plumes with equipment carried in a manned aeroplane 2,3.4. Among other results, we observed both the horizontal and vertical atmospheric electric field components up to 4,000 feet above the chimneys on calm days, when thermal convection of the plume was more pronounced than motion downwind. Rowland ${ }^{5}$ came across the plume phenomena in 1973 when making measurements in a clear air turbulence study.

Vonnegut et al. ${ }^{6}$ purposely generated clouds of charged oil droplets with a device similar to an electrostatic precipitator and reported extremely high local electric fields which caused point corona discharge currents and other high-field effects on bushes, structures, people, etc. He also levitated a charged cloud of water droplets below the oil cloud.

To the extent that charges generated in this manner (by chimney precipitators) can somehow become transferred onto high mobility carriers, the authors may be right in asserting that there is a possible contribution to the earth's charge balance.
We doubt that the low mobility, charged solid particles contribute directly, but the high mobility charges, which they may generate by pulling point discharges from earthed structures, might. The first result of this point discharge current in the atmosphere, of course, will be to help discharge the chimney plume; no doubt this is partly why the electrical effect of the plume is diminished as it travels away from the precipitator.

The observation of a possible hazard from sparking in the near vicinity of such plumes is well taken, and the cement and electrical power industries should be interested in further investigation into this likelihood.

$$
\begin{aligned}
& \text { Yours faithfully, } \\
& \text { MAYNARD L. Hill } \\
& \text { THEODORE R. WHYTE } \\
& \text { Roger O. WeISS }
\end{aligned}
$$

Applied Physics Laboratory,

Johns Hopkins University,

Laurel, Maryland 20810, USA

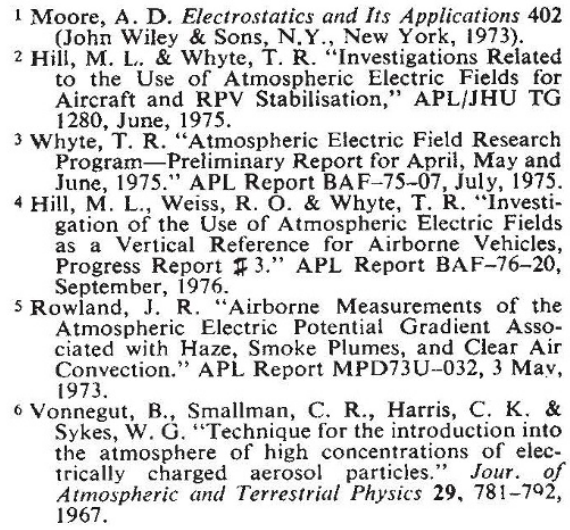

\section{Bird at Pompeii}

SIR,-T. E. Thompson (27 January, page 292) surely owes an apology to the anonymous artist of Pompeii. The little bird he portrayed sitting on a rock overlooking the sea is clearly a composite representation of all those passerine migrants of the type known to Americans as 'confusing fall warblers' which are still trapped and eaten on a vast scale all round the Mediterranean coastline. It is interesting that they are the only terrestrial delicacy considered worthy of inclusion in a picture of local specialties. They are of course those 'nightingales' whose tongues formed the favourite diet of the Roman emperors.

Yours faithfully, W. R. P. BOURne

Milltimber

Aberdeen, UK 